\title{
Research on Protection and Repair Technologies for the Wooden Architec- tures of Chinese Eastern Railway at Yimianpo
}

\author{
Jun Zhang ${ }^{1,2, *}$, Daping Liu ${ }^{1}$ and Li Zhang ${ }^{2}$ \\ ${ }^{1}$ School of Architecture, Harbin Institute of Technology, China; ${ }^{2}$ School of Civil Engineering, Northeast Forestry \\ University, China
}

\begin{abstract}
This paper teases the wooden architectures at Yimianpo in the period of Chinese Eastern Railway, analyzes the construction of the wooden architectures, classifies them according to the wooden structure system, and uses relevant protection and repair technologies for research according to their characteristics, in order to find reasonable protection and repair technologies for the wooden architectures and provide more referable bases for the future protection and repair of the wooden architectures of Chinese Eastern Railway at Yimianpo.
\end{abstract}

Keywords: Chinese eastern railway, protection and repair, wooden architecture, yimianpo.

\section{INTRODUCTION}

The architecture of Chinese Eastern Railway is an important part of industrial heritage, and also an extremely representative railway heritage in China at present, on which the research has developed to a certain degree. Yimianpo Town is located in Harbin-Suifenhe Section of Chinese Eastern Railway, in the southeast $20 \mathrm{~km}$ away from the location of Shangzhi City People's Government, named after a 50mlong gentle slope in the middle of Dazhi Street in the town, where a large number of wooden architectures built in the period of Chinese Eastern Railway are reserved. Such wooden architectures have experienced whirligig of time and have finally become historical buildings. Upon analysis on primary causes, they are not only highly related to the historical background and cultural factors of Yimianpo, but also directly related to local geographical location. Yimianpo Town is ringed on three sides by mountains, rich in forest resources, providing abundant building materials for the construction of such wooden architectures. Thanks to the important role of timbers in the construction of Chinese Eastern Railway, a large number of wooden architectures can be built. The protection and repair of such architectures is an important part of the protection for the historical buildings of Chinese Eastern Railway.

\section{BASIC CONSTRUCTION OF THE WOODEN AR- CHITECTURES}

Most of wooden architectures of Chinese Eastern Railway at Yimianpo have followed the construction style of traditional Russian wooden architectures in terms of structural design and basic construction, mainly made of timbers and stones, reflecting unique features through certain artistic

\footnotetext{
*Address correspondence to this author at the Main Building 521 Room of NEFU, No. 26 at Hexing Road, Xiangfang District of Harbin City, Heilongjiang Province, Postcard: 150040, China; Tel: 13704515827;

E-mail: 13704515827@126.com.
}

and technical processing. Such wooden architectures can be roughly divided into roof, wall and foundation from the general outline.

\subsection{Roof}

Since the town of Yimianpo has a long winter mostly featuring windy and snowy weather, exquisite and simple abrupt-slope iron sheet roof design can not only make wooden architectures form a soft contour line with the sky, but also weaken the wind power and relieve the pressure from snow accumulation to some extent, which is beautiful and pragmatic at the same time. Those decorative timber components under eaves are not only beautiful, but also substantively functional, which can drain rainwater and snow water, and thus reduce the formation of ice pitons. Iron sheet roof tiles are mostly rectangular $(57 \mathrm{~mm} \times 127 \mathrm{~mm}$ and $57 \mathrm{~mm} \times 117 \mathrm{~mm}$ ) and about $2 \mathrm{~mm}$ thick. Transverse and longitudinal roof tiles are connected by seaming, with good leakproofness and water permeability.

\subsection{Wall}

The walls of existing wooden architectures at Yimianpo can be divided into two types according to the style: wood board house (Fig. 1) and log house (namely "Mukeleng"). Wood board houses are mainly built with wood boards, whose outer walls are composed of equi-width and equidistance wood boards with the arrangement mode in different directions, reflecting a rich outer facade effect upon overlapping. The joints of wood boards are concealed, and the column skeleton is wrapped by wood boards (Fig. 2), being beautiful and damp-proof at the same time. For inner walls, gray slats are firstly plastered with raw soil, and then with white lime. Doors, windows and piers between two windows of these wood board houses are lined with wooden architrave decorations, being proportionally coordinated and exquisite, which can not only play the role of protection, but also integrate decoration with functionality. 


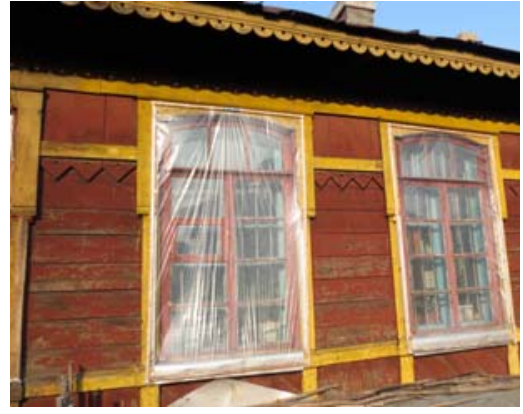

Fig. (1). Outer wall of a wood board house (photographed by authors themselves).

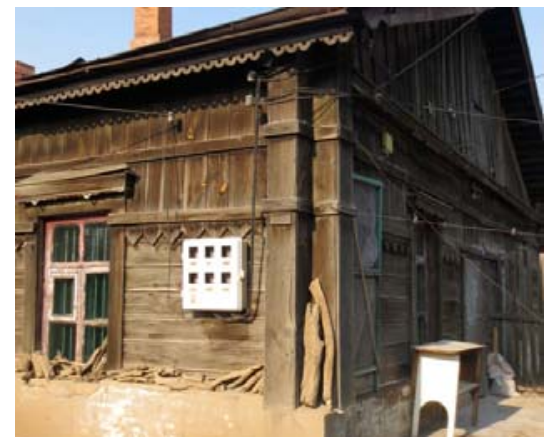

Fig. (2). Column in the corner of a wall (photographed by authors themselves).

Log houses are reinforced with wooden wedges rather than iron nails in the construction process, multiple logs of similar specifications are stacked layer by layer from bottom to top, and corner positions are connected by tenon-andmortise work, with $300 \mathrm{~mm}$ extrusion. The unique texture of $\log$ makes the outer facade naturally form a horizontal layout, which is not only cold or heat resistant, but also beautiful and pragmatic. In Yimianpo Town, there is only one Mukeleng residence reserved now (Fig. 3), built with Korean pine log, whose time of construction is close to the construction time of the railway station cottage, featuring firm and rough overall appearance.

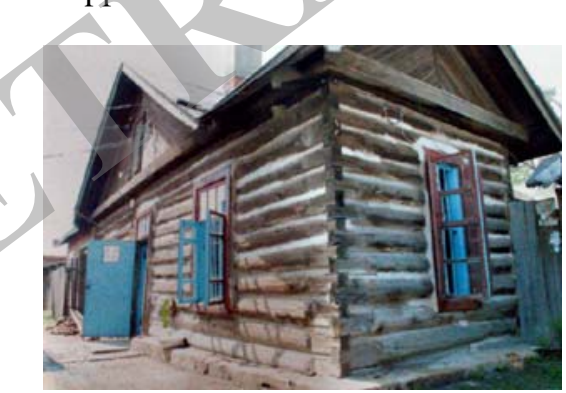

Fig. (3). Mukeleng residence (photographed by authors themselves).

\subsection{Foundation}

The foundations of wooden architectures are piled with stones, solid and steady, and filled with cement, and then covered with a layer of moss derived from the forest which will function as the cement in the seam, being highly airtight. Because of deep foundation, a half-storey or one-storey basement will form, which can not only expand a building's use space, but also skillfully make use of upper temperature difference, so as to reduce the impact of seasonal temperature difference on the building.

\section{CLASSIFICATION OF WOOD MEMBER SYSTEMS}

Along with the invasion of Tsarist Russia, profound technologies and rich experience are also introduced. The historical wooden buildings in Yimianpo Town extend Russia's local wooden structure technologies and form the whole wooden structure system through several wood members. Several wood members are inter-combined and form the wooden structure system, and each wood member will play its own important role [1]. Maybe it is not just limited to single supportive structure role and use functions, but also plays a certain role in decoration. According to wood members' different functions, the whole wood member system can be divided into three categories, namely skeleton members, members for use and decorative members.

\subsection{Skeleton Members}

Skeleton members are primary members to undertake and transfer building load. Among those wooden architectures at Yimianpo Town, skeleton members have played the most important role; they are just like human skeletons and play the main role of supporting, including wood roof trusses composed of wooden member bars such as beams, rafters and columns, wooden walls piled with logs, and wooden pillars used in some larger-span space, etc. (Fig. 4).

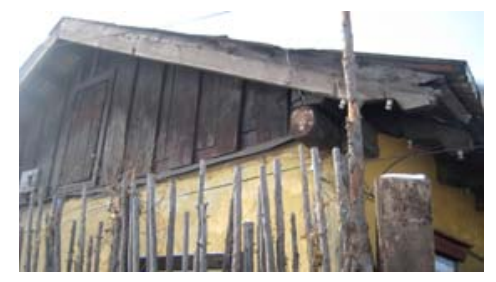

Fig. (4.1). Wood roof truss.

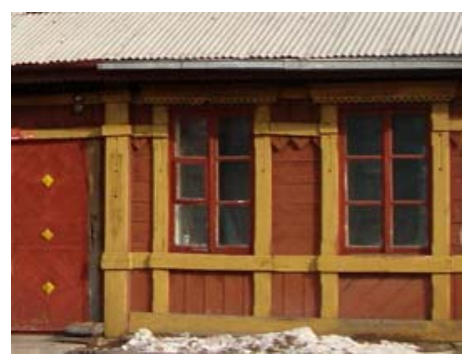

Fig. (4.2). Wooden wall.

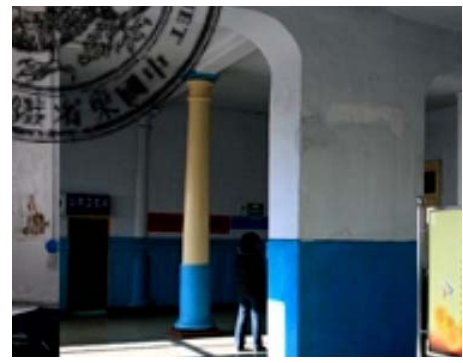

Fig. (4.3). Wooden pillar.

Fig. (4). Skeleton members (photographed by authors themselves). 

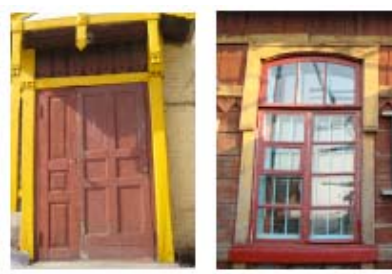

Fig. (5.1). Door and window.

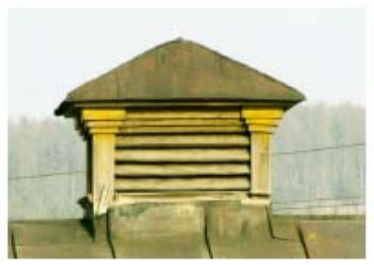

Fig. (5.4). Louver window.

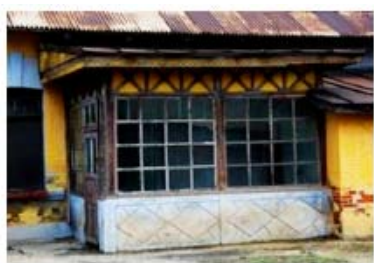

Fig. (5.7). Open corridor.

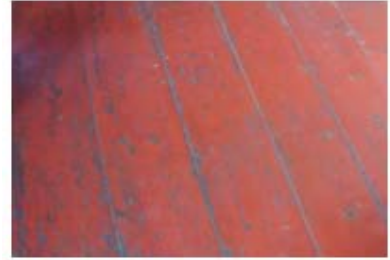

Fig. (5.2). Floor.

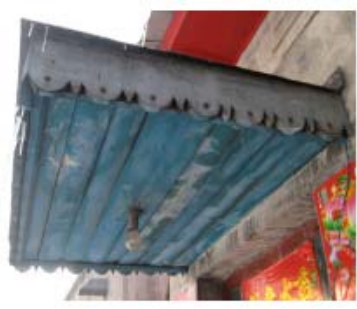

Fig. (5.5). Foyer.

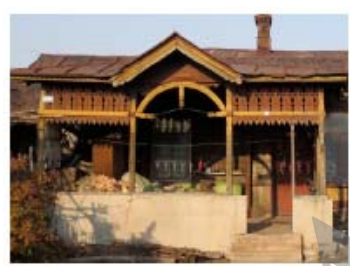

Fig. (5.8). Sunlight room

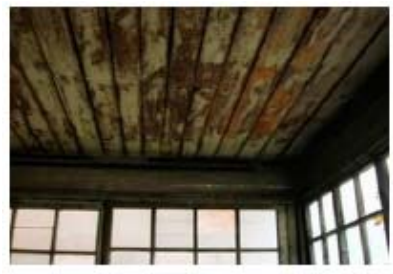

Fig. (5.3). Ceiling.

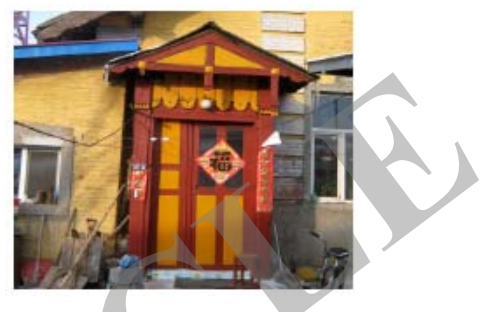

Fig. (5.6). Awning.

Fig. (5). Members for use (photographed by authors themselves).

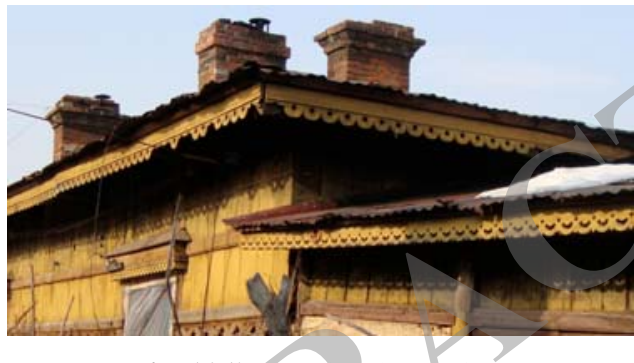

Fig. (6.1). Cornice decoration.

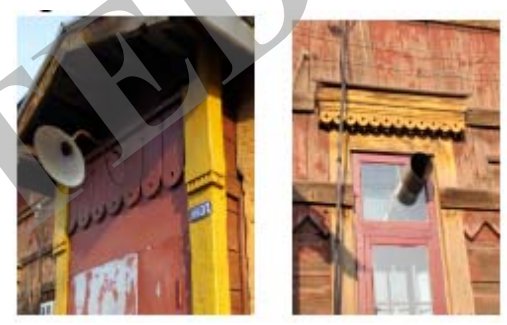

Fig. (6.2). Door and window opening decoration.

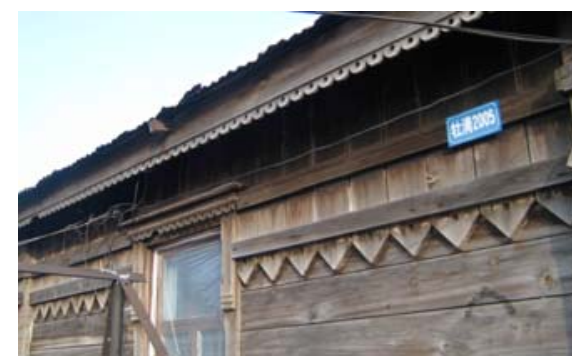

Fig. (6.3). Gable decoration.

Fig. (6). Decorative members (photographed by authors themselves).

\subsection{Members for Use}

Among the wooden structure system, there are some common wood members, such as door and window, floor, ceiling, louver window, foyer, awning, open corridor and sunlight room, with strong usability. Although such wood members play different roles, they can coordinate with each other well, which can not only improve people's living conditions, but also elevate living comfort level (Fig. 5).

\subsection{Decorative Members}

Among wooden architectures, in addition to main skeleton members and members for use, there are also decorative members, known as "the crowning touch" of buildings and mainly applied to cornice, door \& window opening and gable positions (Fig. 6). Compared with brick, stone and other materials, timber has unparallel decoration quality, special beauty, natural and fantastic color, luster and grain, graceful and amiable texture, so it is widely applied to architectural decoration in the railway construction at Yimianpo Town. Such members beautify buildings through unique appearance design and color processing, giving people certain visual enjoyment [2].

\section{REINFORCEMENT OF WOOD STRUCTURES AND REPAIR OF WOOD MEMBERS}

Abundant forest resources at Yimianpo Town provide railway wooden architectures with sufficient building materials, while extensive varieties provide wooden architectures with appropriate completion opportunities. Statistics show that The Yimianpo National Forest Park has about 350 kinds of woody plant, numerous needle-leaved plant such as Larix gmelinii, Korean pine, pinus sylvestris and abies holohylla, as well as some national rare tree species such as northeast China poplar, northeast China ash, autumn walnut and phellodendron amurense, which are also extensively applied to each wood member in the railway construction at Yimianpo Town as building materials. 
Table 1. Classification of repair measures for wood members.

\begin{tabular}{|c|c|}
\hline Repair strategy & Description \\
\hline \hline Keep the original state & The member is in a good condition, only daily maintenance can reach the purpose of protection. \\
\hline Maintain stability and protect & Remove corroded parts and apply chemical materials to reinforce the historical building. \\
\hline Filling-type repair & Use some reinforcement materials for vacancy filling and match them with original building materials. \\
\hline Imitate and replace & Materials cannot be repaired, or the repair cost is much higher than its historical significance. \\
\hline
\end{tabular}

Table 2. Classification of mechanical reinforcement technologies for structures.

\begin{tabular}{|c|c|c|}
\hline $\begin{array}{c}\text { Mechanical } \\
\text { reinforcement technology }\end{array}$ & $\begin{array}{c}\text { Use materials such wood board and steel plate to reinforce damaged members, so as to } \\
\text { strengthen the carrying capacity of wood members, which can also be used for the reinforce- } \\
\text { Increasing structural materi- } \\
\text { als }\end{array}$ & $\begin{array}{c}\text { Applicable to degumming, fracturing and cleaving of wood members; use materials such as } \\
\text { anchor bolt, steel plate and angle iron for reinforcement, so as to avoid further degradation. }\end{array}$ \\
\hline \hline Intensifying seaming & \\
\hline
\end{tabular}

The service time of existing wooden architectures of Chinese Eastern Railway at Yimianpo Town has exceeded the design life far, many durability problems may increasingly emerge with time. As people's study on the industrial heritage of Chinese Eastern Railway draws certain attention and makes certain progress, the protection and repair for existing buildings of Chinese Eastern Railway becomes increasingly important and urgent. Contrasting the damage conditions of existing wooden architectures at Yimianpo Town, the following four repair measures can be respectively taken according to the damage degree of wood members (Table 1).

\subsection{Reinforcement of Wood Structures}

For protection of the historical wooden architectures at Yimianpo Town, the first measure taken should be maintenance and reinforcement. We should select the most appropriate method according to the damage degree of different parts, strictly follow relevant structural reinforcement regulations for repair, and maximally ensure the integrity of the original structure and the authenticity of the original practice and process. Generally, there are two common technologies for the reinforcement of wood structures:

\section{(1) Mechanical reinforcement technology}

This technology will recover the structural strength of the original wood member depending on addition of adapting pieces such as wood and steel, which can be mainly divided into increasing structural materials and intensifying seaming (Table 2):

\section{(2) Epoxy resin reinforcement technology}

Epoxy resin is also frequently used to repair the damaged part of a wood member. When it is applied to non-structural parts, it is mainly applied to water-proof, sealed and other obviously identifiable damaged parts, so as to repair the appearance or avoid any internal corrosion. When it is applied to structural parts, it is mainly used to repair ruptures not obviously identifiable, so as to avoid any internal damage. It is required to inject epoxy resin into ruptures to ensure the strength of members. Epoxy resin is mainly applicable to the following four circumstances (Table $\mathbf{3}$ ):

\subsection{Repair of Wood Members}

The main building materials for the wooden architectures at Yimianpo Town are timbers. Compared with other building materials, timber has unparallel advantages. For instance, timber has beautiful grain, color and luster, which can absorb part of ultraviolet ray and give people a comfortable visual perception and a good touch feel; besides, timber is a kind of natural porous material, with good sound absorption and sound insulation performance [4]. Some timbers are applicable to indoor environment, with moisture absorption and moisture desorption performance, which can regulate indoor RH to some extent. However, if timber is eroded by natural factors for long (such as year-round solar radiation, wind, snow, frost and bacteria corrosion), or damaged by external artificial factors, it may be damaged and even destroyed to some extent. We should take corresponding technical measures according to the damage conditions and damage degree of different wood members.

\section{(1) Finish processing}

For the historical wooden architectures at Yimianpo Town, the paint on the surface of the wood member can not only play the role of protection, but also deliver the peculiarity of Russian architectural color culture as a decorative layer. However, for time, natural force and artificial factors, 
Table 3. Classification of applications of epoxy resin.

\begin{tabular}{|c|c|c|}
\hline $\begin{array}{l}\text { Internal longitudinal cleav- } \\
\text { ing }\end{array}$ & $\begin{array}{l}\text { Frequently appear inside structural members such as truss and beam. Although this damage } \\
\text { has less impact on pressure and tensile, it will severely reduce the shear strength for deflection } \\
\text { resistance. }\end{array}$ & \\
\hline $\begin{array}{l}\text { Structural members are cut } \\
\text { apart }\end{array}$ & $\begin{array}{l}\text { An abrupt fracture at any bolted joint or scab of timber may cause sudden damage to the } \\
\text { structure, and thus reduce the tensile or flexural stress of the structural member. }\end{array}$ & \\
\hline $\begin{array}{l}\text { Corrosion of structural } \\
\text { members }\end{array}$ & $\begin{array}{l}\text { Long-time staying of wood structures in an inappropriate environment may cause corrosion } \\
\text { and severely influence the carrying capacity, not easy to repair, for which only epoxy resin } \\
\text { method can be used. }\end{array}$ & \\
\hline
\end{tabular}

the paint coating on these historical wooden architectures may appear different degrees of peeling and damage (Fig. 7) we should reinforce or recoat it in time.

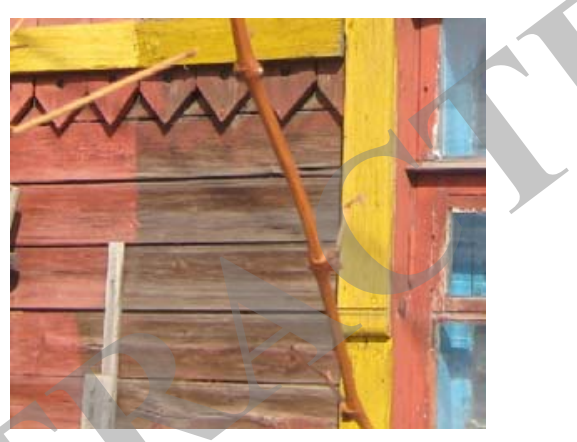

Fig. (7). Peeling of paint coating (photographed by authors themselves).

During finish reinforcement, we should select an reasonable method which can reach the purpose of reinforcement and will not damage timbers, with less impact on the environment. Acrylic resin and polyvinyl acetal can be used, because they have good permeability and strong aging resistance. For local peeling and loss of finish, aniline dye or mineral pigment can be used for color embellishing on the wooden base layer, so as to match it with surrounding color, and then painting and other steps should be taken [5]. When it is required to remove the paint on the surface of wood member, we should select a softer method, and can use weak aqua ammonia and other chemical methods for targeted processing [6].

\section{(2) Crack processing}

Cracking is a common phenomenon in the application process of wood members (Fig. 8), mainly for two reasons: on the one hand, it is caused by adverse factors and improper artificial factors in the environment; on the other hand, it is caused by inconsistent expansion and shrinkage in the dehydration process of timbers. In this case, non-bearing members can evenly mix wood flour, silica flour and other materials with resin, and then fill in and tamp the crack, or use chemical materials such as epoxy resin and water-based glue for crack processing. When bearing wood members show any slight crack (Fig. 9), to ensure their normal carrying capacity, we can use iron hoop for reinforcement according to damage positions and conditions. The size and number of iron hoops should be decided as the case may be. We should first hoop and close the crack, and then use snap fasteners or bolts for joint connection. When the wood member with a crack is rectangular and shows a larger section, we can use U-shaped iron pocket for reinforcement and long bolts for tightening [7].

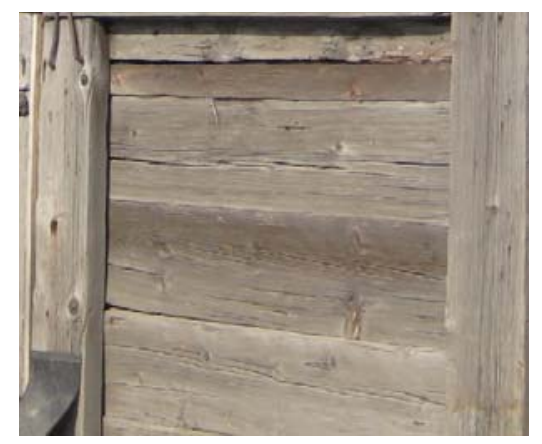

Fig. (8). Wood cracking (photographed by authors themselves).

(3) Decay and anti-corrosion processing

For decay processing of non-bearing members (Fig. 10), we should retain original materials as much as possible, 
scrape and dig decayed parts into columnar, cylindrical, conical and other tractable geometrical shapes, keep the integrity of the dug hole's edge, and remove sundries in the hole. And then we should select a timber of similar color, texture and grain, process and match it to the dug hole's shape, and then use reinforcement materials such as unsaturated polyester resin and epoxy resin for bonding, and finally polish and paint the surface.

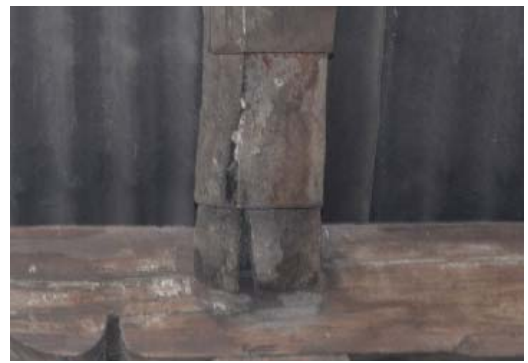

Fig. (9). Member cracking (photographed by authors themselves).

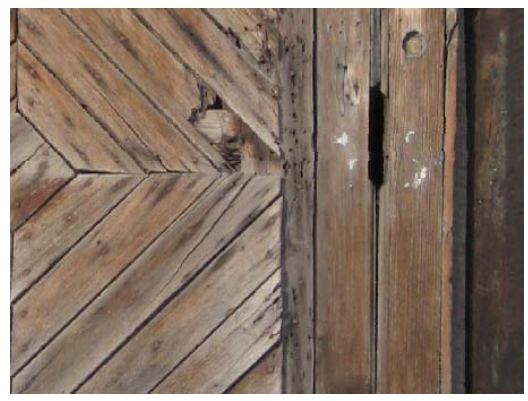

Fig. (10). Wood decay (photographed by authors themselves).

Tenon is a bearing member where decay often appears (Fig. 11), the general processing method is to replace the damaged tenon with a new tenon, connect it to other members, and ensure the authenticity of the original structure to the maximum extent. To ensure structural safety and meet the safety requirements in the regulations, generally speaking, we should use metal members to reinforce the processed tenon joint part and use bolts for connection.

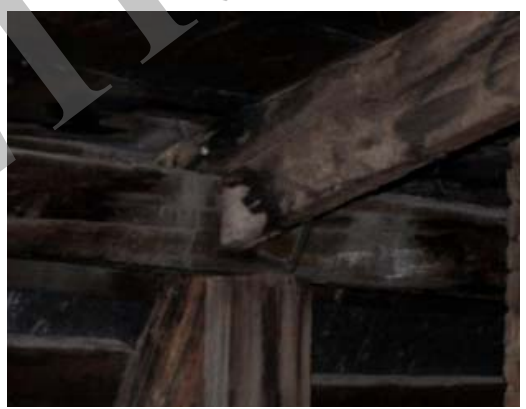

Fig. (11). Tenon decay (photographed by authors themselves).

If many wood members are easy to decay in the application process, for slight damages, we can use chemical methods for anti-corrosion processing. Wood preservatives are generally divided into three types: water-soluble preservative, oil-soluble preservative and oil-based preservative. However, the following requirements should be satisfied [8]: can go deep into the timber, long effective time, less impact on the strength of wood structures, no damage to metal connection, harmless to human body.

\section{(4) Bending and sagging processing}

Long-time bearing of load and pressure may cause certain bending and deformation of the wood structure (Fig. 12), the general processing method is to add members at an appropriate place to share the load borne by the original structure. We can add pillars to support bending or sagging members, or use additional beams to solve deformation problems. For the member easy to bend, sag and deform, it is required to add a support at the tenon-and-mortise work carrying larger shear force, so as to strengthen its carrying capacity. Purline reinforcement method allows addition of purline under it or addition of iron plate to the purline for bending and sagging prevention.

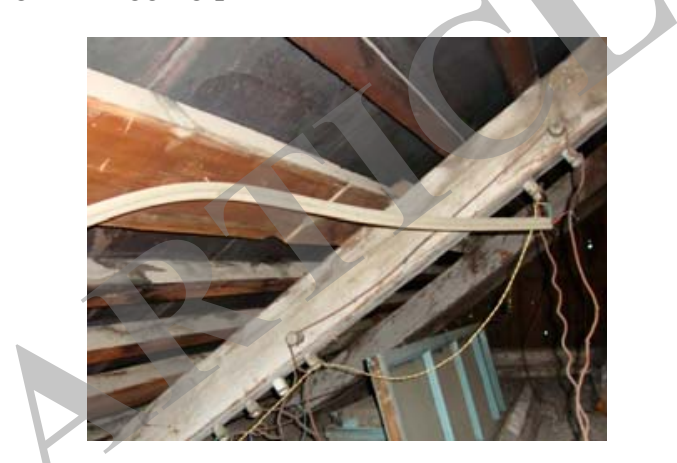

Fig. (12). Bending and sagging of wooden pole (photographed by authors themselves).

\section{(5) Replacement of wood members}

For loss of any wood member (Fig. 13) or failure in repair of any member, replacement is required. During replacement of wood members, we should select similar tree species, try the best to match timbers' color, luster and grain, and strictly follow the original processing technology for fabrication, so as to reduce visual impact and structural impact.

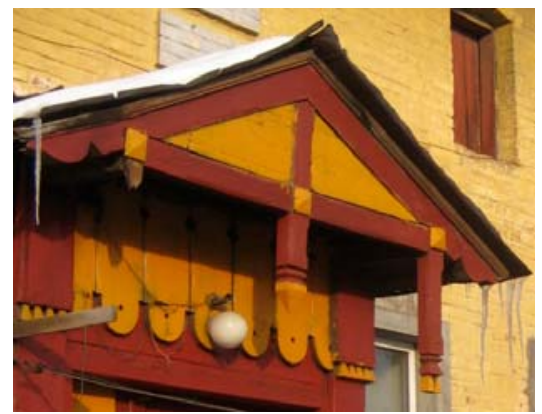

Fig. (13). Loss of member (photographed by authors themselves).

\section{CONCLUSION}

Under the action of multiple natural and artificial factors, the functionality of the wooden architectures of Chinese Eastern Railway at Yimianpo Town is wearing off, for which protection and repair is urgent. However, this should not be carried out blindly, we should respect the authenticity of history, not intentionally cover up the actual conditions of building repair, and attach importance to future protection 
and update. The carding and investigation on the wooden architectures is designed to fundamentally understand their compositions and characteristics, so as to provide a basis and direction for future repair. According to existing conditions of the wooden architectures, we should classify them for damage statistics and select the most reasonable repair scheme according to different protection methods. Only prudent and creative repair can show respect to the creators and respectively win appreciation and respect from successors and users.

The buildings of Chinese Eastern Railway at the town of Yimianpo not only witness a period of history, but also record a period of architectural development process, whose protection and repair is of profound significance. However, all problems related to building repair must be carefully considered and prudently designed, do not blindly carry it out. The protection and repair process needs not only scholars with professional visual angle, but also support from relevant policies and personnel, as well as group participation of the public. Only fundamental improvement of the masses' consciousness can give these historical buildings a unique significance.

\section{CONFLICT OF INTEREST}

The authors confirm that this article content has no conflict of interest.

\section{ACKNOWLEDGEMENTS}

Fund project: Heilongjiang Provincial Natural Science Funding Project (E201257).

\section{REFERENCES}

[1] ZHOU Yonghui, Analysis on the Construction of Modern Wooden Architectures, Southwest Jiaotong University, 2011.

[2] WANG Yingying, Functions, Realization and Development Directions of Architectural Decorative Elements, China New Technologies and Products, 2010, 01: 168.

[3] ZHANG Fan, Research on Modern Historical Building Protection and Repair Technologies and Evaluation, Tianjin University, 2010.

[4] WANG Kai, Health Efficacy and Hazards of Timber to Human Health (1) - Health Efficacy of Timber to Human Health, Forest Product Industry, 2006, 01: 65-67.

[5] ZHANG Juan, Research on Building Material Resource Protection and Reuse Technology Strategy, Tianjin University, 2008.

[6] LENG Jie and ZHANG Xingguo, Wooden Architecture Surface Protection Concepts and Technologies - Take the Protection and Repair Engineering of Chongqing Hu-Guang Guild Hall as an Example, Huazhong Architecture, 2013, 06: 198-202.

[7] LI Kaiwen and JI Min, Dangkou Ancient Town Ancient Building Repair Technologies, Construction Technology, 2012, 21: 78$81+114$.

[8] CAO Jinzhen, Foreign Timber Anti-corrosion Technologies ad Research Status, Forest Science, 2006, 07: 120-126.

flict of interest.

Received: September 16, 2014

Accepted: December 31, 2014

(C) Zhang et al.; Licensee Bentham Open.

This is an open access article licensed under the terms of the Creative Commons Attribution Non-Commercial License (http://creativecommons.org/licenses/by-nc/3.0/) which permits unrestricted, non-commercial use, distribution and reproduction in any medium, provided the work is properly cited. 